\title{
EFEITO DO TEMPO DE ENCHARQUE NA DISSOLUÇÃO DE PRECIPITADOS E NAS PROPRIEDADES MECÂNICAS DE CHAPAS GROSSAS DE AÇOS MICROLIGADOS*
}

\author{
Fábio Dian Murari ${ }^{1}$ \\ Antônio Adel dos Santos ${ }^{2}$ \\ Beatriz Pereda ${ }^{3}$ \\ José María Rodríguez-Ibabe 4 \\ Marcelo Arantes Rebellato ${ }^{5}$
}

\begin{abstract}
Resumo
Investigou-se neste estudo, em escala de laboratório, o efeito do tempo de encharque de placas na dissolução de precipitados e nas propriedades mecânicas de aços microligados ao $\mathrm{Nb}$ e $\mathrm{Ti}$, produzidos como chapas grossas. Para as temperaturas utilizadas, verificou-se que a aplicação de tempo de encharque de até 50 min, após o reaquecimento com tempo de permanência de $250 \mathrm{~min}$, não exerceu influência significativa nas propriedades mecânicas dos aços investigados. Este resultado foi associado à dissolução total de precipitados finos $(<100 \mathrm{~nm})$ durante a etapa de aquecimento e à desprezível dissolução durante a etapa de encharque de precipitados grosseiros, localizados principalmente no centro da espessura da placa, em regiões de microssegregação.
\end{abstract}

Palavras-chave: Reaquecimento de placas; Dissolução de precipitados; Chapas grossas.

\section{THE EFFECT OF SOAKING TIME ON THE DISSOLUTION OF PRECIPITATES AND ON THE MECHANICAL PROPERTIES OF MICROALLOYED STEELS HEAVY PLATES}

\section{Abstract}

The effect of soaking time of slabs on the precipitates dissolution and mechanical properties of $\mathrm{Nb}$-Ti microalloyed steels heavy plates was studied in laboratory scale. At the temperatures practiced, it was found that increasing the soaking time up to $50 \mathrm{~min}$, after a reheating process with residence time of $250 \mathrm{~min}$, did not have any significant influence on the mechanical properties of the investigated steels. This result was associated with the dissolution of fine precipitates $(<100 \mathrm{~nm})$ during the heating step, followed by negligible dissolution, during the soaking step, of the coarse precipitates, which were located mainly in the center of slab thickness, in microsegregation areas.

Keywords: Reheating plates; Precipitates dissolution; Heavy plates.

1 Engenheiro Metalurgista, D. Sc., Pesquisador Especialista, Centro de Pesquisa da Usiminas, Ipatinga, MG, Brasil.

2 Engenheiro Metalurgista, D. Sc., Pesquisador Especialista Senior, Centro de Pesquisa da Usiminas, Ipatinga, MG, Brasil.

3 Engenheira Industrial, Phd., Pesquisadora, Centro de Estudios e Investigaciones Técnicas, Donostia-San Sebastián, Spain.

4 Engenheiro Industrial, Dr.-Eng.; Pesquisador Senior, Centro de Estudios e Investigaciones Técnicas, Donostia-San Sebastián, Spain.

5 Engenheiro Metalurgista, RMS, São Paulo, Brasil. 


\section{INTRODUÇÃO}

O estágio inicial de qualquer processo de deformação a quente é o reaquecimento do material. O objetivo desta etapa é elevar a temperatura para conferir a plasticidade necessária para a conformação e dissolver os precipitados de elementos microligantes existentes, a fim de se garantir a precipitação de finas partículas de segunda fase na matriz metálica durante a laminação e/ou resfriamento da chapa [1].

Dentre os principais elementos microligantes utilizados, o $\mathrm{Nb}$ é considerado o mais importante. Ele desempenha papel fundamental na maioria dos aços processados como chapas grossas por possibilitar a obtenção de uma microestrutura final refinada, a qual permite combinar alta resistência mecânica com elevada tenacidade. Além do efeito refinador de grão, o Nb também contribui com o aumento da resistência pelo mecanismo de endurecimento por precipitação. No entanto, para exercer todo o seu potencial, o $\mathrm{Nb}$ precisa estar dissolvido na matriz ao final do reaquecimento, quando a placa é desenfornada $[2,3]$.

A precipitação durante o lingotamento de aços microligados ao $\mathrm{Ti}$ e $\mathrm{Nb}$ ocorre inicialmente com a formação de precipitados grosseiros do tipo $(\mathrm{Ti}, \mathrm{Nb})(\mathrm{N}, \mathrm{C})$, acima de $1300^{\circ} \mathrm{C}$. Essas partículas geralmente aparecem associadas com inclusões e microssegregação $[4,5]$. Esses precipitados podem ser chamados de primários e dificilmente se dissolvem em condições usuais de reaquecimento de placas. Após a formação desses precipitados, ocorre a nucleação e crescimento de precipitados mais finos, do tipo $(\mathrm{Nb}, \mathrm{Ti})(\mathrm{C}, \mathrm{N})$, com diferentes morfologias e razões $\mathrm{Ti} / \mathrm{Nb}$. Como no caso anterior, o núcleo desses precipitados geralmente é mais rico em Ti e N [4,6-9] Esse tipo de precipitado pode ser dissolvido durante o reaquecimento da placa, resultando no aumento do $\mathrm{Nb}$ em solução sólida antes da etapa de laminação.

De modo geral, durante a etapa de reaquecimento, após a temperatura de encharque ser atingida, o material pode permanecer no forno por um tempo mínimo, normalmente de até $50 \mathrm{~min}$, para que haja a homogeneização da temperatura ao longo da espessura da placa e para que o processo de dissolução dos precipitados contendo $\mathrm{Nb}$ seja favorecido.

Dentro desse contexto, investigou-se neste trabalho, em escala de laboratório, o efeito do tempo de encharque (tENC) na dissolução de precipitados de $\mathrm{Nb}$ e nas propriedades mecânicas de aços microligados produzidos como chapas grossas.

\section{MATERIAIS E MÉTODOS}

Foram utilizadas amostras de placas de quatro aços microligados ao $\mathrm{Nb}$ e $\mathrm{Ti}$, cujos teores de $\mathrm{C}, \mathrm{Nb}, \mathrm{Ti}$ e $\mathrm{N}$ são mostrados na Tabela 1. As amostras foram cortadas em blocos, com largura entre $120 \mathrm{~mm}$ e $200 \mathrm{~mm}$, comprimento de $250 \mathrm{~mm}$ e mesma espessura das placas (aproximadamente $250 \mathrm{~mm}$ ). Os blocos laterais foram descartados e os blocos localizados no centro da largura da placa foram utilizados no estudo da dissolução dos precipitados. Os demais foram utilizados na etapa de laminação em escala piloto. 
Tabela 1. Composição química dos aços investigados

\begin{tabular}{cccccc}
\hline \multirow{2}{*}{ Aço } & \multicolumn{5}{c}{ Composição química (\% em massa) } \\
\cline { 2 - 6 } A & $\mathbf{C}$ & $\mathbf{N b}$ & $\mathbf{T i}$ & $\mathbf{N}$ & Ti/N \\
\hline B & 0,087 & 0,019 & 0,024 & 0,0035 & 6,9 \\
C & 0,038 & 0,032 & 0,006 & 0,0026 & 2,3 \\
D & 0,074 & 0,046 & 0,016 & 0,0038 & 4,2 \\
\hline
\end{tabular}

Com base na composição química mostrada na Tabela 1, foram realizados cálculos, utilizando-se o software Thermo-Calc, para previsão da fração molar e da temperatura de dissolução dos precipitados.

\subsection{Caracterização Inicial dos Precipitados nas Placas}

As análises para caracterização dos precipitados nas amostras retiradas de placas, na condição inicial, foram realizadas via microscopia óptica (MO), microscopia eletrônica de varredura (MEV) e microscopia eletrônica de transmissão (MET). As análises foram realizadas em subamostras retiradas a $1 / 4$ e $1 / 2$ da espessura das placas, visando à obtenção de informações com relação ao tamanho dos precipitados, morfologia e composição química. Nas análises de MET, foram utilizadas réplicas de extração de C.

\subsection{Efeito do Tempo de Encharque na Dissolução dos Precipitados}

Nesta etapa, foram utilizadas subamostras com largura entre $80 \mathrm{~mm}$ e $100 \mathrm{~mm}$ (na direção da largura da placa), cerca de $120 \mathrm{~mm}$ de comprimento e $30 \mathrm{~mm}$ de espessura, retiradas a $1 / 4$ e a $1 / 2$ da espessura do bloco selecionado.

Os tratamentos térmicos, realizados em um forno de resistência elétrica e atmosfera não controlada, consistiram no reaquecimento das subamostras até as temperaturas de encharque mostradas na Tabela 2. As subamostras atingiram as temperaturas desejadas após 250 min de permanência no forno. Alcançada a temperatura de encharque, as subamostras permaneceram no forno por $0 \mathrm{~min}, 15 \mathrm{~min}, 30 \mathrm{~min}$ e 50 min e, em seguida, foram temperadas em água a temperatura ambiente, para preservação do estado de dissolução dos precipitados, cuja caracterização foi feita da mesma forma que nas placas.

Tabela 2. Temperaturas de encharque utilizadas nos tratamentos dos aços

\begin{tabular}{cc}
\hline Aço & $\mathbf{T}\left({ }^{\circ} \mathbf{C}\right)$ \\
\hline A & 1150 \\
B & 1150 \\
C & 1180 \\
D & 1220 \\
\hline
\end{tabular}

\subsection{Laminação a Quente}

\subsubsection{Reaquecimento}

$\mathrm{Na}$ etapa de reaquecimento, subamostras com $125 \mathrm{~mm}$ de espessura, $170 \mathrm{~mm}$ de largura (na direção da largura da placa) e $240 \mathrm{~mm}$ de comprimento, retiradas do centro da espessura dos blocos selecionados, foram aquecidas até as temperaturas mostradas na Tabela 2 e retiradas do forno para laminação em três condições: 0 min, 30 min e 50 min de encharque. Para a obtenção dessas subamostras, foram retirados $62,5 \mathrm{~mm}$ de material a partir de cada superfície dos blocos (espessura 
original dos blocos: $250 \mathrm{~mm}$ ), de modo que a linha de segregação central ficou alinhada com o centro da subamostra laminada. Dessa forma, foi possível avaliar a condição mais crítica em relação à dissolução dos precipitados.

\subsubsection{Processamento termomecânico}

Após o desenfornamento, os aços avaliados foram laminados em escala piloto. A laminação de desbaste foi iniciada a uma temperatura próxima à de reaquecimento, terminando em temperatura superior à temperatura de não recristalização (Tnr). A laminação de acabamento, por sua vez, foi iniciada abaixo da Tnr, para todos os aços, sendo o último passe efetuado acima da temperatura de início de transformação $\gamma / \alpha(\operatorname{Ar} 3)$ para os aços B, C e D. Para efeito de simplificação, todos os aços foram submetidos à mesma escala de passes, a qual resultou em uma espessura final de $18 \mathrm{~mm}$. Após a laminação de acabamento, as chapas dos aços B e $C$ foram submetidas a resfriamento acelerado, enquanto as dos aços $A$ e $D$ a resfriamento ao ar, seguido de normalização em forno de atmosfera controlada no caso deste último. Foram realizadas análises de precipitados e de inclusões em seções retiradas das chapas laminadas.

\subsection{Caracterização das Propriedades de Tração}

Os ensaios de tração foram realizados em máquina Instron modelo 5882 , segundo a norma ASTM A370 [10], a temperatura ambiente e a uma taxa de deformação média de $10^{-3} \mathrm{~s}^{-1}$. Foram ensaiados, para cada condição avaliada, três corpos de prova (CPs) retangulares sub-size (base de medida de $25 \mathrm{~mm}$ ), retirados do centro da espessura das chapas, com eixo maior transversal à direção de laminação. A caracterização mecânica em tração foi feita em termos de limite de escoamento, limite de resistência e alongamento total.

\subsection{Ensaios de Impacto Charpy}

Foram realizados ensaios de impacto Charpy a temperatura de $-20^{\circ} \mathrm{C}$ em corpos de prova do tipo full-size com entalhe em " $V$ " e com as dimensões estabelecidas pela norma ASTM E23 [11]. Foram ensaiados quatro corpos de prova para cada condição, os quais foram retirados no centro da espessura das chapas e orientados transversalmente à direção de laminação.

\section{RESULTADOS E DISCUSSÃO}

\subsection{Cálculo da Fração Molar e da Temperatura de Dissolução dos Precipitados}

Na Figura 1(a) é mostrada a fração molar dos precipitados primários, do tipo $(\mathrm{Ti}, \mathrm{Nb})(\mathrm{N}, \mathrm{C})$, em função da temperatura, para os quatro aços analisados. Como se pode observar, os aços com maior razão Ti/N apresentaram maior fração desses precipitados e também maior temperatura de dissolução, o que implica em partículas mais grosseiras nesses materiais. Por outro lado, o aço $\mathrm{B}$, com menor razão Ti/N e baixo teor de $\mathrm{C}$, apresentou os menores valores de fração molar de precipitados e menor temperatura de dissolução, sugerindo a formação de partículas mais finas e mais efetivas no ancoramento dos grãos austeníticos. Na Figura 1(b) é mostrada a variação da fração molar de precipitados do tipo $(\mathrm{Nb}, \mathrm{Ti})(\mathrm{C}, \mathrm{N})$, em função da temperatura. Como comentado anteriormente, um dos objetivos da etapa de 
reaquecimento é dissolver completamente esses precipitados. Comparando-se os dados apresentados na Figura 1(b) e Tabela 2, verifica-se que, com exceção do aço $\mathrm{D}$, todos os demais apresentaram temperatura de dissolução prevista pelo ThermoCalc inferior à temperatura de encharque utilizada. Analisando a Figura 1(b), observa-se, ainda, que a elevação dos teores de $\mathrm{C}$ e $\mathrm{Nb}$, como era esperado, provocou o aumento da fração molar e da temperatura de dissolução dos precipitados.

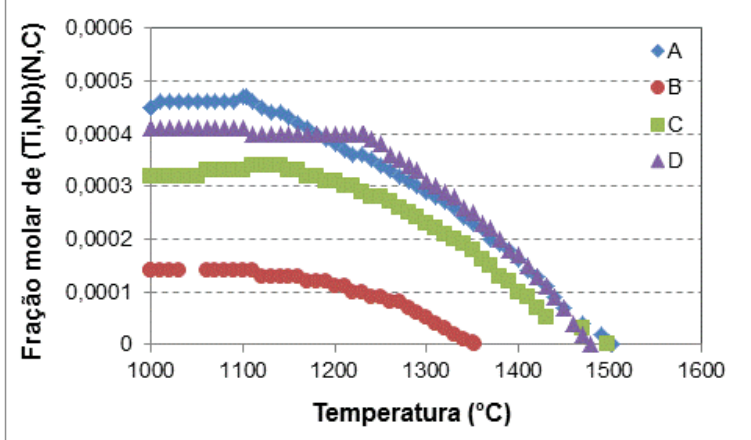

(a)

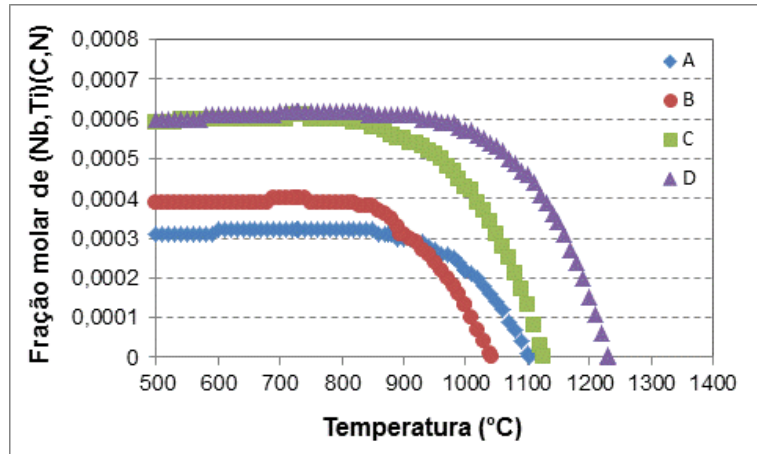

(b)

Figura 1. Fração molar de $(\mathrm{Ti}, \mathrm{Nb})(\mathrm{N}, \mathrm{C})$, parte $(\mathrm{a})$, e $(\mathrm{Nb}, \mathrm{Ti})(\mathrm{C}, \mathrm{N})$, parte $(\mathrm{b})$, em função da temperatura para os quatro aços estudados. Valores previstos pelo Thermo-Calc 2016b/TCFE6.

\subsection{Caracterização Inicial dos Precipitados - Condição de Placa}

Na Figura 2 são mostradas regiões com presença de precipitados grosseiros no centro da espessura das amostras analisadas. No caso do aço A, foram observados precipitados decorando os contornos de grãos da austenita prévia, associados a inclusões de $\mathrm{MnS}$ (partículas escuras). Para o aço $\mathrm{B}$, poucos precipitados grosseiros isolados foram observados no centro da espessura, confirmando as previsões via Thermo-Calc. Precipitados alinhados, como os que são mostrados para o aço $A$, dificilmente foram observados nesse aço. Com relação aos aços $C$ e $D$, também se observou a presença de precipitados grosseiros alinhados ao longo dos contornos de grãos prévios ou de forma isolada na matriz, geralmente em regiões contendo sulfetos. Na Figura 3 são mostrados resultados de análise via MEV/EDS (Espectroscopia de Energia Dispersiva) de precipitados encontrados no aço A. 


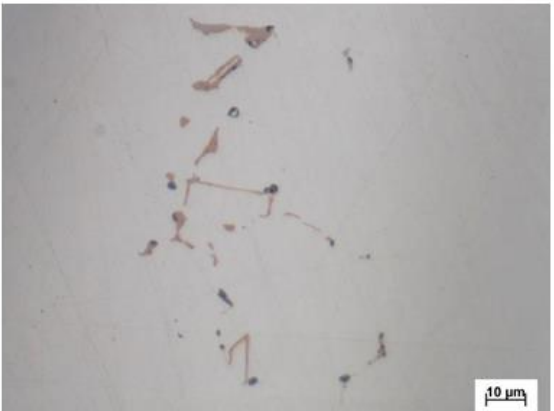

(a) Aço A

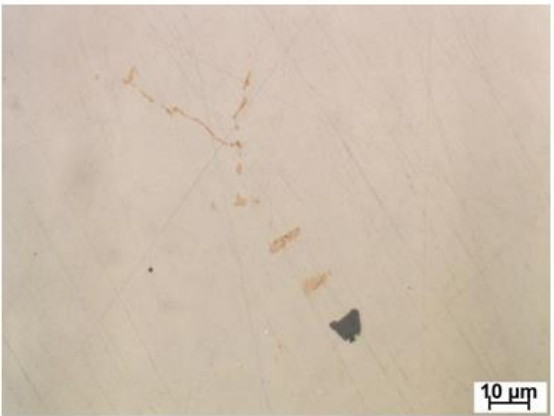

(c) Aço C

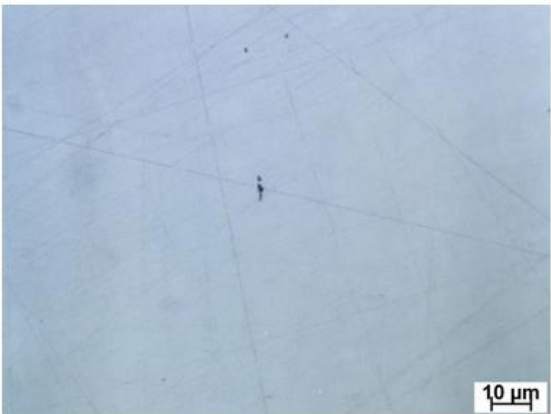

(b) Aço B

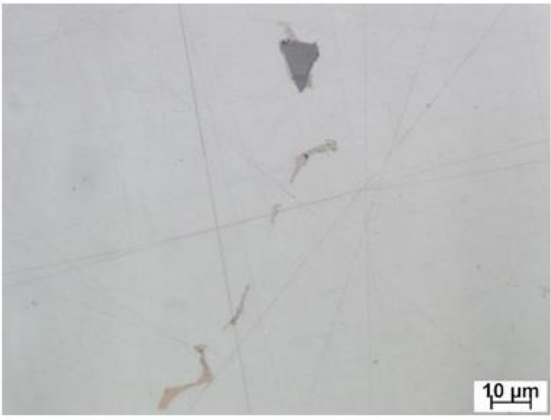

(d) Aço D

Figura 2. Aspecto de precipitados grosseiros encontrados no centro da espessura dos aços analisados. Seções polidas. MO.

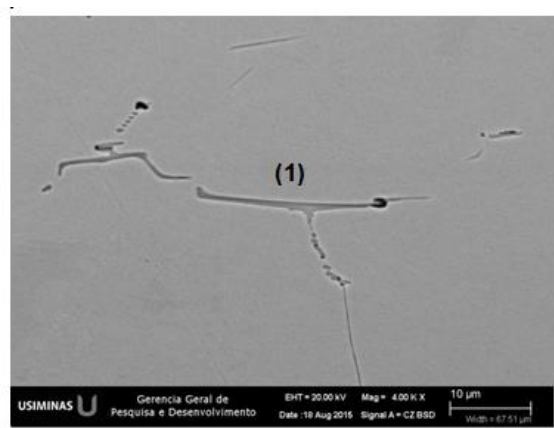

(a)

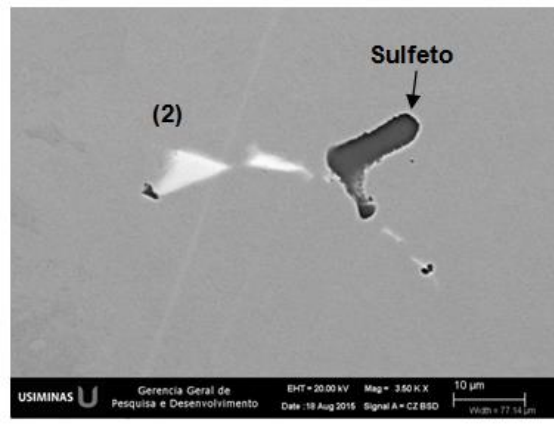

(c)

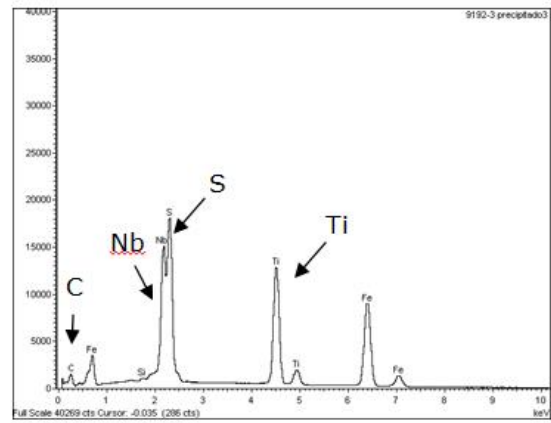

(b)

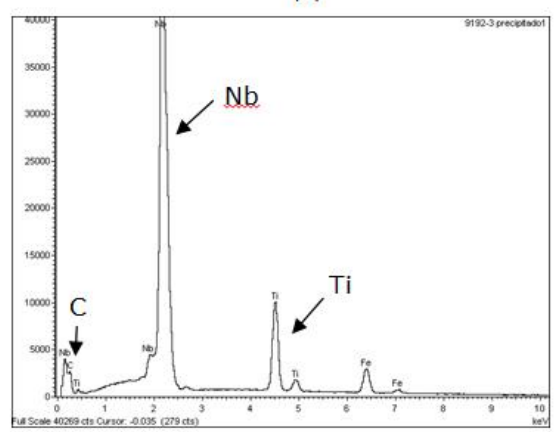

(d)

Figura 3. (a) e (c) Aspecto de precipitados grosseiros encontrados no centro da espessura do aço $A$. (b) Resultado de EDS realizado em partícula mostrada em (a), identificada como (1). (d) Resultado de EDS realizado em partícula mostrada em (c), identificada como (2). Seção polida, paralela à direção de lingotamento. MEV.

Na Figura 4 são apresentados resultados de MET para o aço A. Pode-se observar a presença abundante de precipitados do tipo $(\mathrm{Nb}, \mathrm{Ti})(\mathrm{C}, \mathrm{N})$, muitas vezes na forma de aglomerados. Foram encontrados precipitados cruciformes e na forma de estrelas 
(20 $200 \mathrm{~nm})$, alongados $(20 \sim 200 \mathrm{~nm})$, retangulares/cúbicos $(20 \sim 600 \mathrm{~nm})$ e precipitados muito finos $(<10 \mathrm{~nm})$, de formato esférico. As análises realizadas via EDS mostraram que as partículas eram ricas em $\mathrm{Nb}$ e Ti, com diferentes razões de $\mathrm{Nb} / \mathrm{Ti}$, Figuras 5 e 6 . O estado de precipitação para o aço B foi muito heterogêneo. Algumas áreas das réplicas estavam livres de precipitados, enquanto em outras foram observados aglomerados de partículas. Foram identificadas, principalmente, partículas na forma de estrela, cuboidais e arredondadas com tamanho inferior a $100 \mathrm{~nm}$, além de precipitados finos, menores que $10 \mathrm{~nm}$. Para os aços C e D, observou-se precipitação abundante, semelhante à do aço $\mathrm{A}$.

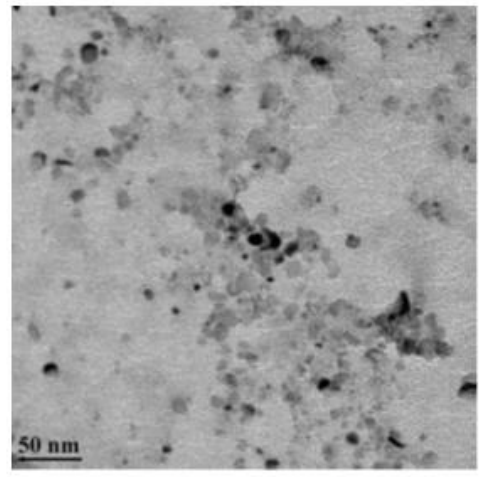

(a) Precipitados esféricos

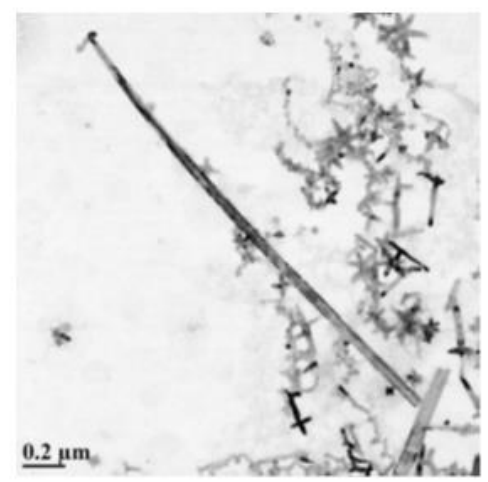

(c) Precipitados na forma de agulhas

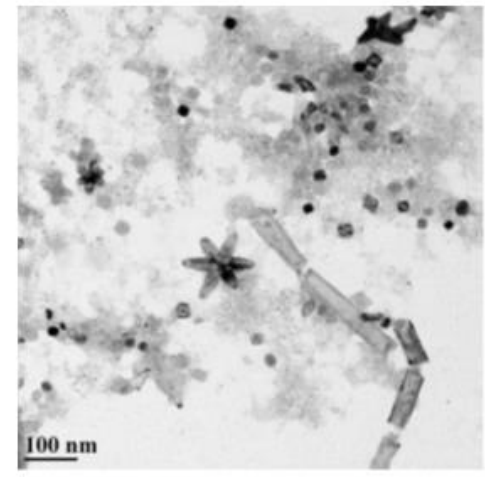

(b) Precipitados cruciformes, na forma de estrelas e retangulares

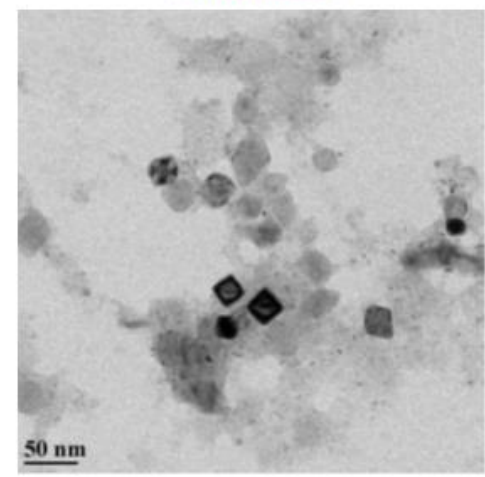

(d) Precipitados cúbicos

Figura 4. (a) Precipitados finos (< $10 \mathrm{~nm}$ ). (b) Precipitados cruciformes, na forma de estrelas e retangulares. (c) Precipitados na forma de agulha, cruciformes e na forma de estrelas. (d) Precipitados cúbicos. $1 \frac{1}{2}$ da espessura. Aço A. MET.

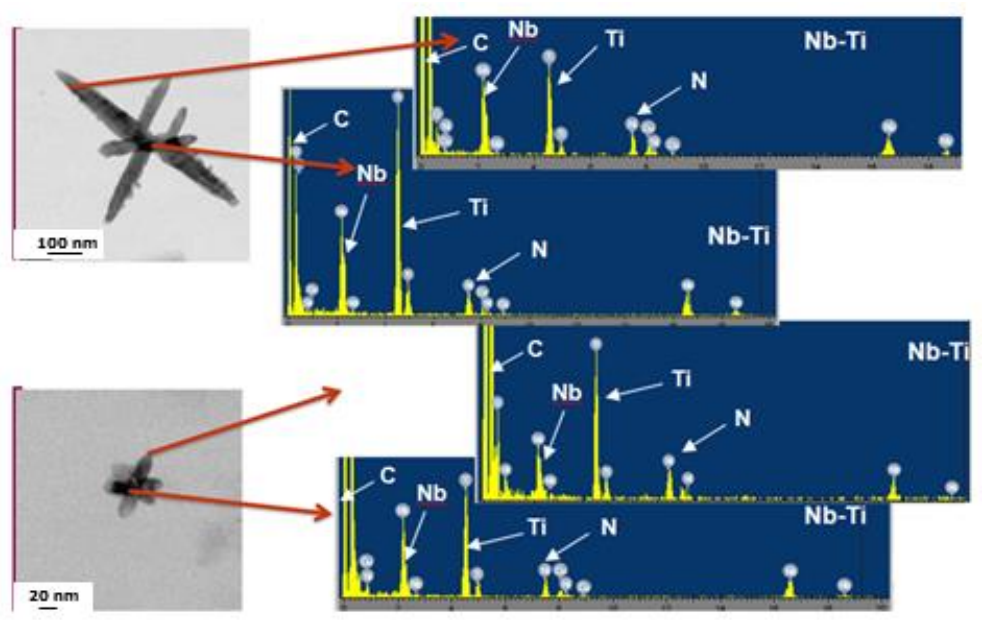

Figura 5. Resultados de EDS nos precipitados cruciformes. Aço A. 1/2 da espessura. MET. 


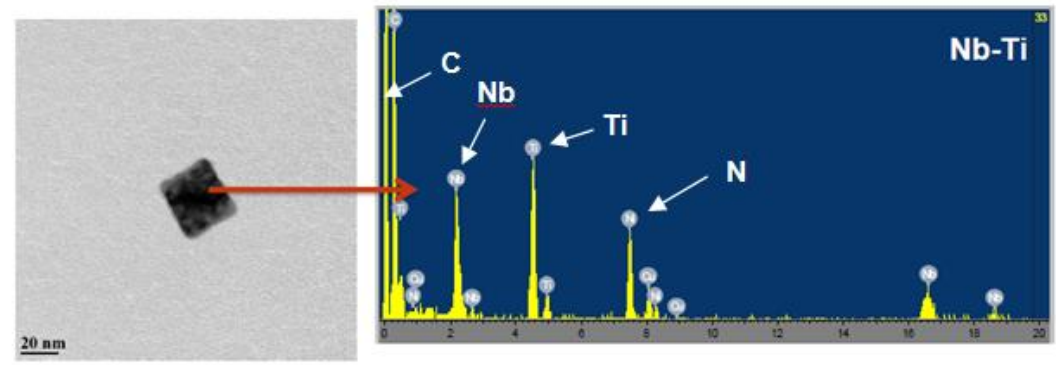

Figura 6. Resultados de EDS em um precipitado cúbico. Aço A. 1/2 da espessura. MET.

\subsection{Efeito do Tempo de Encharque na Dissolução dos Precipitados}

A variação do tempo de encharque entre 0 min e $50 \mathrm{~min}$, para a temperatura de $1150^{\circ} \mathrm{C}$, não exerceu influência significativa na dissolução dos precipitados grosseiros, ricos em Ti do tipo $(\mathrm{Ti}, \mathrm{Nb})(\mathrm{N}, \mathrm{C})$, formados no aço $\mathrm{A}$, Figura 7 , o que era esperado em função da alta temperatura de dissolução dessas partículas, Figura 1(a). Vale ressaltar que os precipitados foram observados em regiões de segregação e associados com inclusões de sulfetos, as quais apresentaram aspecto alongado, o que se deve ao fato das seções terem sido retiradas de amostras laminadas. Resultados semelhantes foram observados para os aços C e D. Para o aço $B$, não foram observados precipitados desse tipo após o aquecimento. Foram observadas apenas inclusões (a maioria óxidos globulares), as quais, obviamente, não foram influenciadas pelo tempo de encharque.

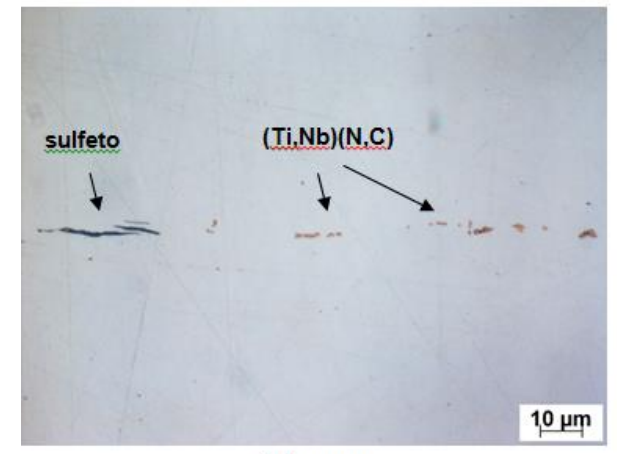

(a) 0 min

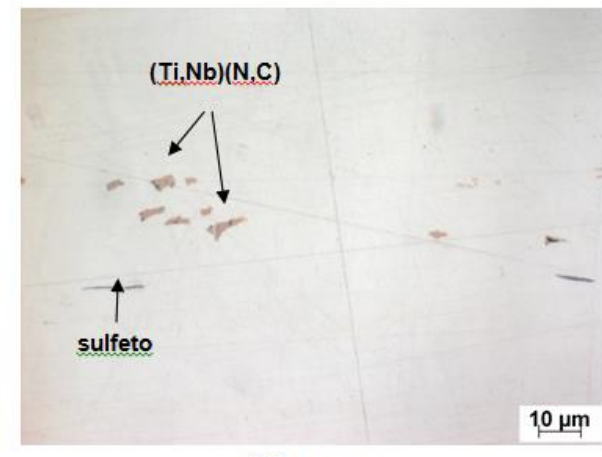

(b) $30 \mathrm{~min}$

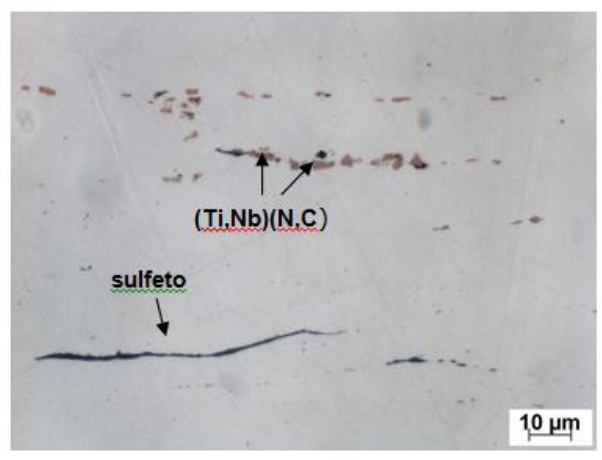

(c) $50 \mathrm{~min}$

Figura 7. Efeito do tempo de encharque na dissolução dos precipitados grosseiros formados no aço A. Temperatura de reaquecimento: $1150^{\circ} \mathrm{C}$. Seção paralela à direção de lingotamento. $1 / 2$ da espessura. MO.

Comparando o estado de precipitação antes, Figura 4, e após a etapa de reaquecimento a $1150^{\circ} \mathrm{C}$, Figura 8, é possível notar que os precipitados cruciformes, 
na forma de estrelas e agulhas e os precipitados finos foram dissolvidos durante 0 processo de aquecimento, até a temperatura de encharque (tENC $=0 \mathrm{~min}$ ), restando os precipitados cúbicos e na forma de paralelepípedos, precipitados esféricos, talvez núcleos dos precipitados cruciformes, e os precipitados facetados, com tamanho das arestas/diâmetro variando de $20 \mathrm{~nm}$ até valores acima de $100 \mathrm{~nm}$. Com relação ao aumento do tempo de encharque para $50 \mathrm{~min}$, Figura 9, o efeito mais significativo foi a redução do teor de $\mathrm{Nb}$ nos precipitados, tornando-os mais ricos em Ti, conforme relatado na literatura [6-9], acompanhada de pequena redução de tamanho. De modo semelhante ao aço $A$, os únicos precipitados do tipo $(\mathrm{Nb}, \mathrm{Ti})(\mathrm{C}, \mathrm{N})$ detectados após reaquecimento, para tempos de encharque entre 0 min e $50 \mathrm{~min}$, para os aços $\mathrm{B}, \mathrm{C}$ e $\mathrm{D}$, foram os cúbicos, retangulares e ovais, com tamanho variando de 15 a $100 \mathrm{~nm}$ e com razões $\mathrm{Nb} /(\mathrm{Nb}+\mathrm{Ti})$ inferiores às das placas.

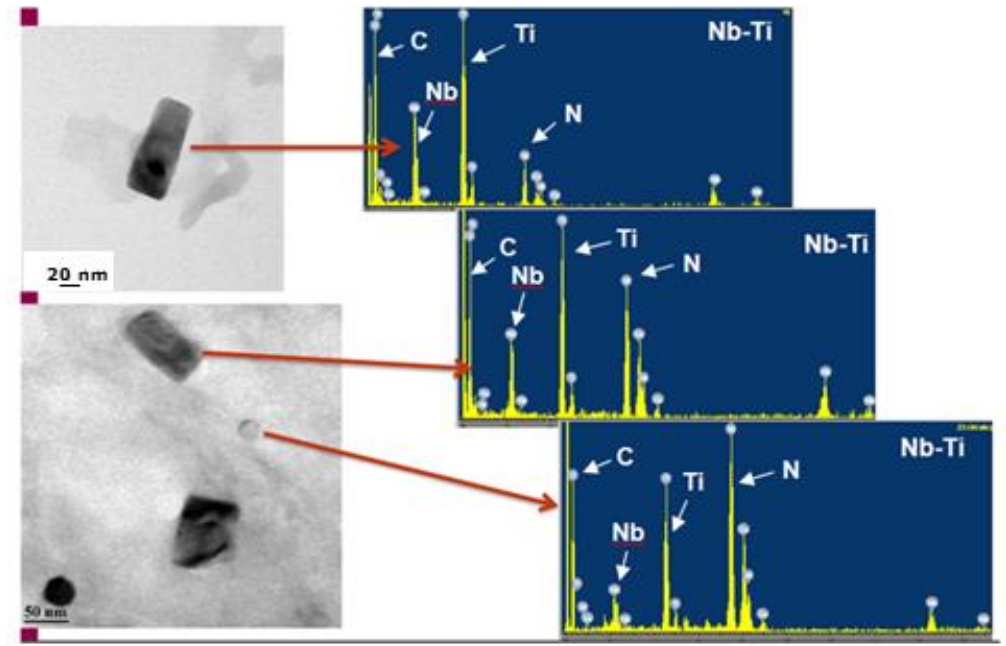

Figura 8. Resultados de EDS evidenciando a presença de $\mathrm{Nb}$ e Ti nos precipitados, com diferentes razões $\mathrm{Nb} / \mathrm{Ti}$. Reaquecimento: $1150^{\circ} \mathrm{C} / 0 \mathrm{~min}$. Aço A. $1 / 2$ da espessura. MET.
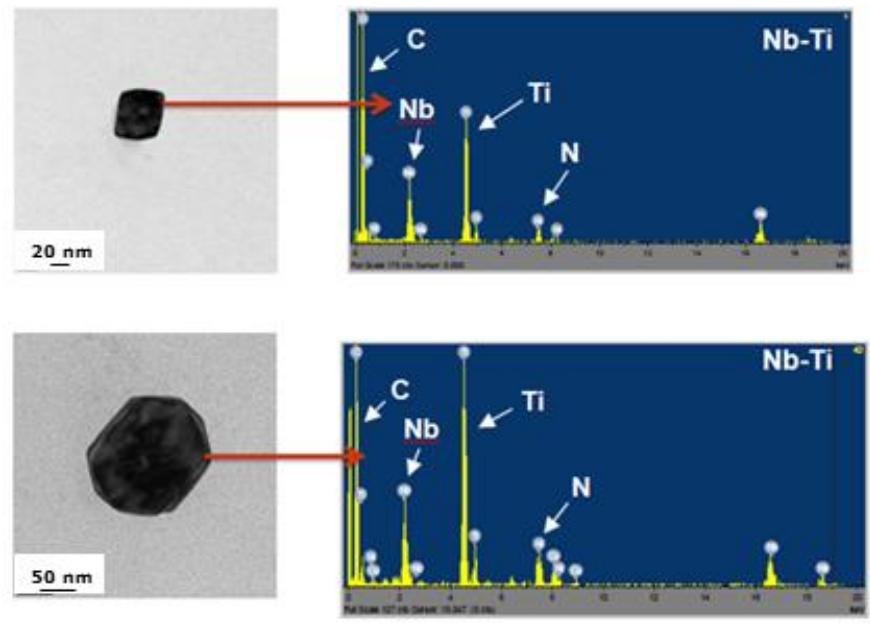

Figura 9. Resultados de EDS evidenciando a presença de $\mathrm{Nb}$ e Ti nos precipitados, com diferentes razões $\mathrm{Nb} / \mathrm{Ti}$. Reaquecimento: $1150^{\circ} \mathrm{C} / 50 \mathrm{~min}$. Aço A. $1 / 2$ da espessura. MET.

Na Tabela 3 é apresentado um resumo do estado de precipitação antes e após o reaquecimento das amostras de placas dos aços analisados. Todos os aços com razão $\mathrm{Ti} / \mathrm{N}$ acima da estequiométrica $(3,42)$ apresentaram precipitados grosseiros (> $1 \mu \mathrm{m})$, ricos em Ti, de forma abundante na condição de placa, com destaque para o aço D. Esses precipitados permaneceram praticamente inalterados após as etapas 
de aquecimento e encharque nos aços $A$ e $D$. No aço $C$ esses precipitados foram observados de forma mais escassa e em menor tamanho. Com relação ao aço $B$, esses precipitados foram observados apenas na condição de placa, apresentando tamanho e fração bastante reduzidos. Os precipitados esféricos finos $(<10 \mathrm{~nm})$, cruciformes/estrelas/agulhas e cúbicos/retangulares/ovais foram observados em todas as amostras de placa, sendo os dois primeiros grupos totalmente dissolvidos antes do encharque. Os do terceiro grupo dissolveram-se apenas parcialmente durante o encharque. A dissolução parcial dessa população de precipitados implica em uma quantidade de $\mathrm{Nb}$ que não estará disponível para a precipitação durante a laminação a quente, reduzindo a possibilidade de se obter austenita devidamente condicionada. Embora a presença dessas partículas em aços microligados ao $\mathrm{Ti}-\mathrm{Nb}$ seja inevitável, sua fração pode ser modulada por uma adequada razão Ti/N.

Tabela 3. Características dos precipitados nos aços analisados.

\begin{tabular}{|c|c|c|c|c|c|c|}
\hline Aço & $\mathrm{Ti} / \mathrm{N}$ & Condição & $\begin{array}{c}\text { Precipitados } \\
\text { finos } \\
(<10 \mathrm{~nm})\end{array}$ & $\begin{array}{l}\text { Precipitados } \\
\text { cruciformes/ } \\
\text { Estrelas }\end{array}$ & $\begin{array}{l}\text { Precipitados } \\
\text { cúbicos/ } \\
\text { Retangulares/ } \\
\text { Ovais }\end{array}$ & $\begin{array}{c}\text { Precipitados } \\
\text { maiores que } \\
1 \mu \mathrm{m} \text { ricos } \\
\text { em Ti }\end{array}$ \\
\hline \multirow{3}{*}{ A } & & Placa & $\uparrow$ & $\uparrow$ & $\uparrow$ & $\uparrow$ \\
\hline & 6,85 & $0 \mathrm{~min}$ & $\downarrow$ & $\downarrow$ & $\uparrow$ & $\uparrow$ \\
\hline & & $50 \mathrm{~min}$ & $\downarrow$ & $\downarrow$ & $\uparrow$ & $\uparrow$ \\
\hline \multirow{3}{*}{ B } & & Placa & $\uparrow$ & $\uparrow$ & $\uparrow$ & $\searrow$ \\
\hline & 2,31 & $0 \mathrm{~min}$ & $\downarrow$ & $\downarrow$ & $\nabla$ & $\downarrow$ \\
\hline & & $50 \mathrm{~min}$ & $\downarrow$ & $\downarrow$ & $\searrow$ & $\downarrow$ \\
\hline \multirow{3}{*}{ C } & & Placa & $\uparrow$ & $\uparrow$ & $\uparrow$ & $\uparrow$ \\
\hline & 4,21 & $0 \mathrm{~min}$ & $\downarrow$ & $\downarrow$ & $\uparrow$ & $y$ \\
\hline & & $50 \mathrm{~min}$ & $\downarrow$ & $\downarrow$ & $\uparrow$ & $\searrow$ \\
\hline \multirow{3}{*}{ D } & & Placa & $\uparrow$ & $\uparrow$ & $\uparrow$ & $\uparrow \uparrow$ \\
\hline & 8,18 & 0 min & $\downarrow$ & $\downarrow$ & $\uparrow$ & $\uparrow \uparrow$ \\
\hline & & 50 min & $\downarrow$ & $\downarrow$ & $\uparrow$ & $\uparrow \uparrow$ \\
\hline & abunds & & não foram c & letectados & esc & issos \\
\hline
\end{tabular}

\subsection{Efeito do Tempo de Encharque nas Propriedades Mecânicas}

Na Figura 10 é mostrado o efeito do tempo de encharque nas propriedades mecânicas dos aços analisados. Observa-se que não houve influência significativa do tempo de encharque, para a faixa avaliada, nos valores de limite de escoamento, limite de resistência, alongamento total e energia absorvida em ensaio de impacto Charpy a $-20^{\circ} \mathrm{C}$. Esse comportamento está de acordo com os resultados apresentados na seção 3.3, podendo ser associado à dissolução de precipitados finos $(<100 \mathrm{~nm})$, menos estáveis, durante a etapa de aquecimento e à não dissolução ou dissolução apenas parcial de precipitados grosseiros, mais estáveis, localizados principalmente no centro da espessura (região de segregação central), durante a etapa de encharque. Como as regiões que contêm os precipitados mais estáveis representam uma pequena fração do volume total do material (a maior parte é de regiões pobres (dendríticas) e de regiões interdentríticas menos ricas em precipitados, em relação àquelas localizadas no centro da espessura), a dissolução que ocorre nelas é insuficiente para causar variações significativas de propriedades mecânicas.

Os resultados apresentados na Figura 10(d) também sugerem uma relevante influência das partículas grosseiras de $(\mathrm{Ti}, \mathrm{Nb})(\mathrm{N}, \mathrm{C})$ nos valores de energia absorvida. Os valores obtidos para os aços $B$ e $C$ correspondem a um comportamento completamente dúctil (upper self region), sendo a diferença de 
energia absorvida obtida entre eles explicada, pelo menos em parte, em função do maior limite de escoamento do aço $C$. Para os aços $A$ e $D$, é razoável assumir que a $-20^{\circ} \mathrm{C}$ eles estão na região de transição dúctil-frágil, o que pode ser correlacionado com a maior presença de partículas grosseiras nesses materiais. Essas partículas agem como sítios para nucleação de trincas por clivagem, reduzindo a tenacidade do material [9]. Conforme foi apresentado na Tabela 3, as etapas de reaquecimento e encharque não foram capazes de modificar ou reduzir a presença dessas partículas no produto final.

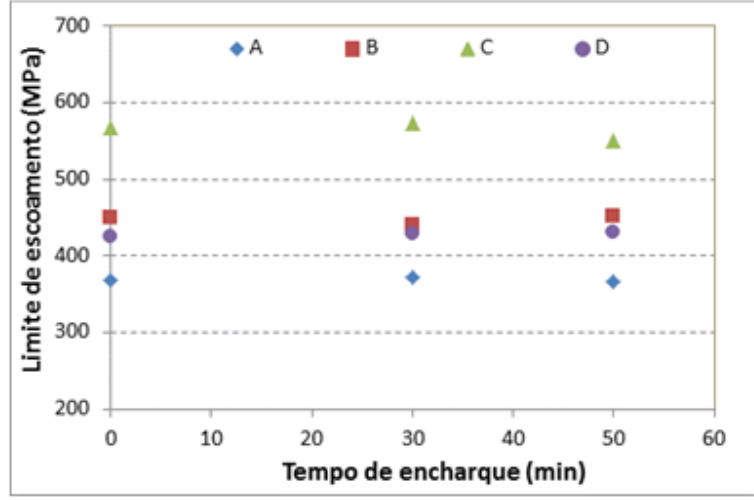

(a)

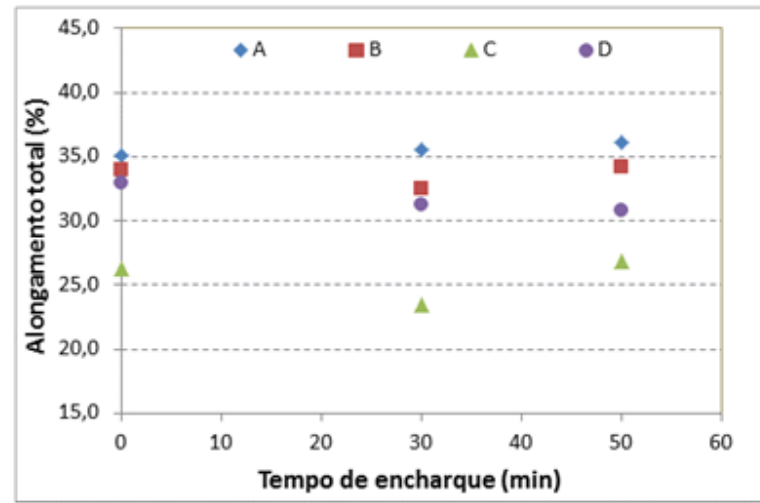

(c)

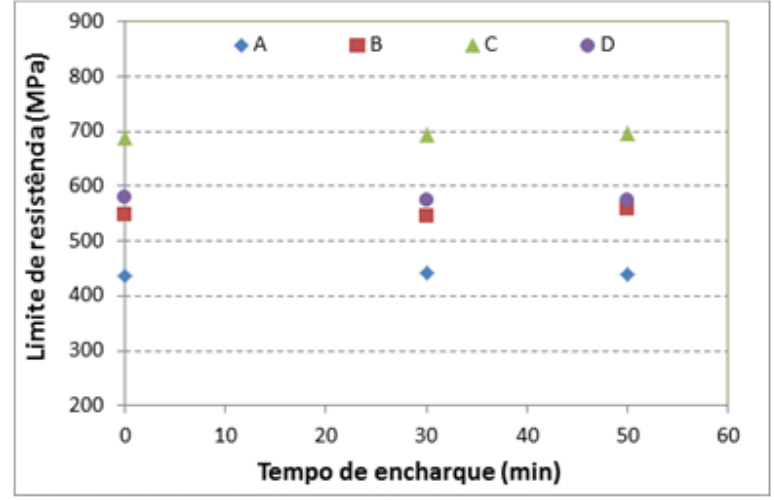

(b)

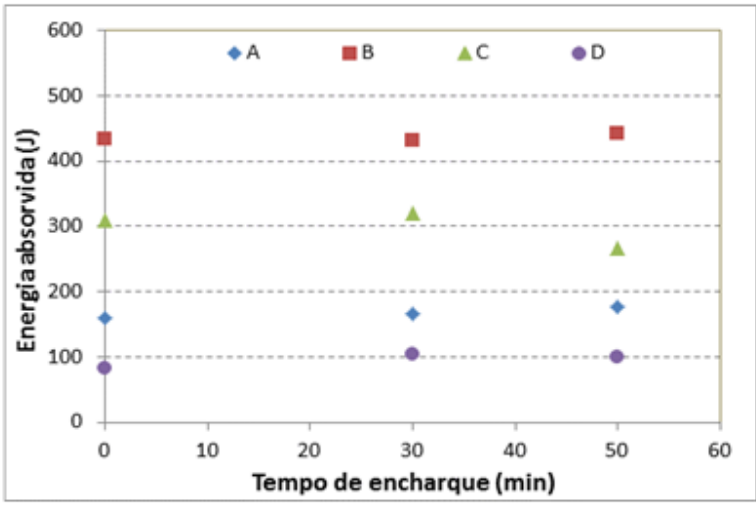

(d)

Figura 10. Efeito do tempo de encharque nas propriedades mecânicas dos aços analisados.

Temperatura do ensaio Charpy: $-20^{\circ} \mathrm{C}$.

\section{CONCLUSÃO}

Para os aços avaliados na condição de placa, foram encontrados precipitados cúbicos, ricos em $\mathrm{Ti}$ e $\mathrm{N}$, com comprimento de aresta superior a $1 \mu \mathrm{m}$, formados em alta temperatura, e também partículas menores, formadas em temperaturas mais baixas, contendo $\mathrm{Nb}, \mathrm{Ti}, \mathrm{C}$ e N, com tamanho na faixa entre $10 \mathrm{~nm}$ e $600 \mathrm{~nm}$. Essas partículas apresentaram diferentes morfologias: (i) cúbica arredondada/oval $(\sim 10 \mathrm{~nm})$; (ii) agulha $(20 \sim 200 \mathrm{~nm})$; (iii) cruciforme/estrela $(20 \sim 200 \mathrm{~nm})$ e (iv) retangular/cúbica $(20 \sim 600 \mathrm{~nm})$. Após aquecimento com tempo de permanência de $250 \mathrm{~min}$ até as temperaturas de encharque, além dos precipitados grosseiros, apenas precipitados cúbicos e retangulares, com tamanho entre 20 e $100 \mathrm{~nm}$, foram detectados, sendo os demais dissolvidos completamente. Após 50 min adicionais de tratamento, os mesmos tipos de precipitados foram observados, com características de forma e tamanho similares, indicando não ter havido dissolução adicional significativa com o aumento do tempo de encharque, para a faixa avaliada. Foram 
observadas apenas alterações na razão $\mathrm{Nb} /(\mathrm{Nb}+\mathrm{Ti})$, indicando o empobrecimento dos precipitados em Nb. Como consequência, não houve influência significativa do tempo de encharque nas propriedades mecânicas. Verificou-se, também, que razões de $\mathrm{Ti} / \mathrm{N}$ acima do valor estequiométrico $(3,42)$ e a presença de segregação e de inclusões de sulfeto de manganês favoreceram a formação de precipitados de Ti e $\mathrm{Nb}$ grosseiros $(>1 \mu \mathrm{m})$, os quais não se dissolvem em condições usuais de reaquecimento de placas.

\section{Agradecimentos}

Os autores agradecem à CBMM, que viabilizou a realização das análises por microscopia eletrônica de transmissão.

\section{REFERÊNCIAS}

1 Jung $\mathrm{HJ}$, Kang KB, Park CG. Effects of cooling rate and isothermal holding on the precipitation behavior during continuous casting of $\mathrm{Nb}-\mathrm{Ti}$ bearing HSLA steels. Scripta. Materialia, 2003, 49, pp. 1081-1086.

2 Zheng S, Davis C, Strangwood M. Elemental segregation and subsequent precipitation during solidification of continuous cast $\mathrm{Nb}-\mathrm{V}$-Ti high-strength lowalloy steels. Materials Characterization, 95, 2014, pp. 94-104.

3 Nishioka K, Ichikawa K. Progress in thermomechanical control of steel plates and their commercialization. Science and Technology of advanced materials. 13 (2012). pp. 1-20.

4 Chen Z, Loretto $\mathrm{MH}$, Cochrane RC. Nature of large precipitates in titaniumcontaining HSLA steels. Materials Science and Technology, London, v. 3, n. 10, 1987, October, pp. 836-844.

5 Zhou C, Priestner R. The evolution of precipitates in Nb-Ti microalloyed steels during solidification and post-solidification cooling. ISIJ International, Japan, v. 36, n. 11, 1996, pp. 1397-1405.

6 Carboni MC, Mesquita RA, Cruz EB, Fridman DP, Nogueira MAS. Caracterização de precipitados em regiões segregadas de um aço $\mathrm{API}-\mathrm{X} 70$ microligado ao Nb. 42ํㅡㄴ Seminário de Aciaria da ABM. Salvador, ABM, 2011, pp. 476-488.

7 Chakrabarti D, Davis C, Strangwood M. Development of Bimodal Grain Structures in Nb-Containing High-Strength Low-Alloy Steels During Slab Reheating, Metallurgical and Materials Transactions A, volume 39A, August, 2008, pp. 1963-1977.

8 Schiavo CP, Gonzalez BM, Santos AA, Marra, KM. Influência dos parâmetros de solubilização temperatura e tempo de encharque na $T_{N R}$ de um aço microligado ao Nb, V e Ti. Tecnol. Metal. Mater. Miner., São Paulo, v. 8, 2011, pp. 14-18.

9 Rodriguez-lbabe JM. The role of microstructure in toughness behavior of microalloyed steels. Mater. Sci. Forum, 284-286, 1998, pp. 51-62.

10 AMERICAN SOCIETY FOR TESTING AND MATERIALS, Philadelphia. ASTM A-370 - 17; Standard Test Methods and Definitions for Mechanical Testing of Steel Products.

11 AMERICAN SOCIETY FOR TESTING AND MATERIALS, Philadelphia. ASTM E23 - 16b; Standard Test Methods for Notched Bar Impact Testing of Metallic Materials. 